\title{
Pelagic movements of pacific leatherback turtles (dermochelys coriacea) highlight the role of prey and ocean currents
}

\author{
Robert S Schick ${ }^{1,2^{*}}$, Jason J Roberts ${ }^{1}$, Scott A Eckert ${ }^{3,4}$, Patrick N Halpin ${ }^{1}$, Helen Bailey ${ }^{5}$, Fei Chai ${ }^{6}$, Lei Shi ${ }^{6}$
} and James S Clark ${ }^{1}$

\begin{abstract}
Background: Leatherback turtles are renowned for their trans-oceanic migrations. However, despite numerous movement studies, the precise drivers of movement patterns in leatherbacks remain elusive. Many previous studies of leatherback turtles as well as other diving marine predators have analyzed surface movement patterns using only surface covariates. Since turtles and other marine predators spend the vast majority of their time diving under water, an analysis of movement patterns at depth should yield insight into what drives their movements.

Results: We analyzed the movement paths of 15 post-nesting adult female Pacific leatherback turtles, which were caught and tagged on three nesting beaches in Mexico. The temporal length of the tracks ranged from 32 to 436 days, and the spatial distance covered ranged from 1,532 km to $13,097 \mathrm{~km}$. We analyzed these tracks using a movement model designed to yield inference on the parameters driving movement. Because the telemetry data included diving depths, we extended an earlier version of the model that examined surface only movements, and here analyze movements in 3-dimensions. We tested the effect of dynamic environmental covariates from a coupled biophysical oceanographic model on patch choice in diving leatherback turtles, and compared the effects of parameters measured at the surface and at depth. The covariates included distance to future patch, temperature, salinity, meridional current velocity (current in the north-south direction), zonal current velocity (current in the east-west direction), phytoplankton density, diatom density, micro-plankton density, and meso-zooplankton density. We found significant, i.e. non-zero, correlation between movement and the parameters for oceanic covariates in 8 of the tracks. Of particular note, for one turtle we observed a lack of correlation between movements and a modeled index of zooplankton at the surface, but a significant correlation between movements and zooplankton at depth. Two of the turtles express a preference for patches at depth with elevated diatoms, and 2 turtles prefer patches with higher mezozooplankton values at depth. In contrast, 4 turtles expressed a preference for elevated zooplankton patches at the surface, but not at depth. We suggest that our understanding of a marine predator's response to the environment may change significantly depending upon the analytical frame of reference, i.e. whether relationships are examined at the surface, at depth, or at different temporal resolutions. Lastly, we tested the effects of accounting for ocean currents on the movement patterns and found that for 13 of the 15 turtles, the parameter governing distance to the next patch decreased.

(Continued on next page)
\end{abstract}

\footnotetext{
* Correspondence: rss5@st-andrews.ac.uk

${ }^{1}$ Nicholas School of the Environment and Earth Sciences, Duke University, Durham, NC 27708, USA

${ }^{2}$ Centre for Research into Ecological and 808 Environmental Modelling, The Observatory Buchanan Gardens, University of St. Andrews, St. Andrews, Fife KY16 9LZ, Scotland, UK

Full list of author information is available at the end of the article
} 
(Continued from previous page)

Conclusions: Our results suggest that relationships derived from the analysis of surface tracks may not entirely explain movement patterns of this highly migratory species. Accounting for choices in the water column has shown that for certain individual turtles, what appears to be favourable habitat at depth is quantitatively different from that at the surface. This has implications for the analysis of the movements and diving behaviour of any top marine predator. The leatherback turtle is a deep diving reptile, and it is important to understand the subsurface variables that influence their movements if we are to precisely map the spatial dimensions of favorable leatherback habitat. These results present a new view into the drivers of diving patterns in turtles, and in particular represent a way of analyzing movements at depth that can be extended to other diving species.

Keywords: Movement, Bayesian, Habitat suitability, Water column, Diving, Leatherback turtles, Marine predator, Dynamic covariates, Prey

\section{Background}

Despite analytical and technological advancements in studying animal movements, our ability to statistically quantify these interactions has lagged; this lapse is especially acute in marine systems characterized by dynamic environments in which animal movements and habitat selection occur in 3 dimensions. The lag in marine systems has been due in part to the fact that many covariates that are used in models of marine animal movement come from remote sensing, e.g. sea surface temperature, chlorophyll $\mathrm{A}$, etc. It is becoming increasingly apparent in marine systems that the processes happening at depth may inform our understanding of the biology more than those happening at the surface [1-7].

The application of state-space modeling methods to animal movement data [8-10], has provided ecologists with tools to enable a substantive advance in our approach to inference on animal habitat use from movement data. Because these analytical methods separate the movement process from our observation of that process [11], they yield inference on the animal's movement choices. Marine ecologists have taken advantage of these techniques, yet it has been argued that for further progress to be made, we must pay more attention to biologically motivated process models [12]. That is, rather than pay attention to how movement phenomena differ in different landscapes [9], we may want to focus on how animals make movement choices in response to dynamic landscapes [12]. Here we bring this modeling approach to bear on moving leatherback turtles from the Eastern Pacific. To understand how individual turtles respond to a dynamic seascape, we apply a hierarchical Bayesian movement model $[12,13]$ to movement tracks of 15 post-nesting adult female turtles. Results from this approach allow us to quantify how individuals are responding to dynamic covariates through time and through the water column.

Marine turtles have been the subject of numerous satellite telemetry studies [14]. Godley et al. [14] describe a general understanding of sea turtle movement types that has emerged. Following other reviews of turtle movements [15], Godley et al. [14] note that the use of satellite tagging to follow turtle movements has led to an understanding of 4 distinct movement phenotypes. These include turtles that feed in the neritic zone (Types A1-A3), and turtles that are fully oceanic feeders (Type B), of which the leatherback is the exemplar. Morrealle et al. [16] were the first to publish on the dramatic movements of east Pacific leatherback turtles, followed by Eckert and Sarti [17] for leatherbacks that nest in Mexico. Morreale's original work from Costa Rica [16] has recently been augmented by a movement study on the same population [18]. Finally, recent studies have re-analyzed the data from these pioneering studies as well as including new data from both western and eastern Pacific populations [19-21].

Morreale et al. [16] noted that we had much to learn from the post-hoc analysis of movements in conjunction with the oceanic environment. From a simple visualization of how turtle movements change in different oceanic habitats, to a more complete understanding of the interplay between physical forcing and biological interactions, Luschi et al. [15] argued that the interaction between biology and physical oceanography is where much progress can be made. And indeed, many studies have stressed the role of oceanography in turtle movements [15,22-27]. Luschi et al. [15] note that currents can play (at least) three different roles: 1) as large scale advective forces; 2 ) as smaller scale features like meanders and eddies; and 3) as features that aggregate prey (sensu Olson et al. [28]). Both Girard et al. [29] and Gaspar et al. [25] independently documented ways to quantitatively separate the movements of the turtle from the movements of the turtle as affected by surface currents. This separation is important in order to understand how turtles may actively use currents in homing [29], and to delineate true area-restricted search [25]. Though research has continued along this line $[18,20,21,30]$, much of this work has rested on overlaying relocations, or behaviorally classified relocations on top of environmental variables. In contrast, Eckert et al. 
[31] combined modeling techniques from Jonsen et al. [32] and from Morales et al. [9] to further our understanding of movement types in dynamic environments. Despite this work, Godley et al. [14] stress that the interplay between the biology of the turtle, the biology of their prey, and the physics of the ocean environment is still an area of research need.

Here we address that need by applying a hierarchical Bayesian movement model [12,13] that exploits choices made by moving turtles to make inference on the suitability of the dynamic landscape as perceived by the turtle. We use this modeling approach to go from data (observed locations of individual turtles, and calculated values of covariates from a 4D oceanographic model) to estimates of a hidden process, namely choices about habitat suitability. Our estimates of the parameters that govern the movement choices of leatherback turtles enable us to quantitatively depict the organism-environment interaction. In addition the results enable further understanding of how turtles change their response to disturbance (e.g. El Niño/La Niña), regime shifts (e.g. Pacific Decadal Oscillation), and climate change.

\section{Results and discussion}

The initial set of results from which all other results and inference arise are the median posterior estimates of the $\beta$ parameters along with their 95\% Bayesian Credible Interval (BCI) for each turtle (Table 1). (We present tabular results for the two surface models in Additional file 3; results from the multi-state model are not presented.) To aid interpretation, recall the bounds within which each of these parameters is proposed in the Gibbs sampler (See Additional files 1, 2, and 3 for the code). For the distance to patch parameter, we assumed the response to be negative and linear. That is, patches farther away from the animal are less favorable. For each of the 6 oceanographic inputs, we assumed there was an envelope response; hence we estimate both a linear and quadratic term for a total of 12 parameters. The linear term is unconstrained, which the quadratic term is constrained to be negative. For example in: $X_{j k, t-1} \beta=x_{1, j k, t-1}$ $\beta_{1}+x_{2, j k, t-1} \beta_{2}+x_{2, j k, t-1}^{2} \beta_{3}+\cdots+x_{p, j k, t-1} \beta_{p}$ proposals for $\beta_{3}$ would be constrained such that $-50<\beta^{\prime}<0$., If the $95 \%$ BCI for a linear parameter includes zero, we would infer this covariate does not have a strong influence on the turtle's movement decisions (Table 1). For example, the posterior estimate for the $\beta$ parameter for turtle 10's response to diatoms is $3.55(-2.28,12.63)$ (median, and $95 \% \mathrm{BCI}$, respectively), and therefore it is likely that turtle 10 's movements were not influenced by diatoms.

The results from the two surface models build on present understanding of how swimming leatherbacks exploit their environment. Specifically, accounting for
Table 1 Qualitative summary of the two models, surface and water column, which compares the best set of inputs within each model

\begin{tabular}{|c|c|c|c|c|c|c|c|}
\hline Turtle & $\begin{array}{l}\text { Distance } \\
\text { to patch }\end{array}$ & $\begin{array}{c}\text { Phyto } \\
\text { plankton }\end{array}$ & Diatoms & $\begin{array}{c}\text { Micro } \\
\text { zooplankton }\end{array}$ & $\begin{array}{c}\text { Meso } \\
\text { zooplankton }\end{array}$ & Temp & Salinity \\
\hline 1 & $x$ & $x$ & $x$ & & $x$ & $x$ & \\
\hline 3 & $x$ & & & $x$ & $x$ & & \\
\hline 3 & $x$ & & $x$ & $x$ & $x$ & & \\
\hline 4 & $x$ & & $x$ & & $x$ & & \\
\hline 4 & $x$ & & & & & & \\
\hline 6 & $x$ & $x$ & & & & & \\
\hline 6 & $x$ & & & & & & \\
\hline 7 & $x$ & & & & & & \\
\hline 7 & $x$ & & & & & & \\
\hline 8 & $x$ & & & & & & \\
\hline 8 & $x$ & & & & $x$ & $x$ & \\
\hline 10 & $x$ & & & & $x$ & & \\
\hline 10 & $x$ & & $x$ & & $x$ & & \\
\hline 11 & $x$ & & & & $x$ & & \\
\hline 11 & $x$ & & & & & & \\
\hline 13 & $x$ & & & & & & \\
\hline 13 & $x$ & & & & & & \\
\hline 16 & $x$ & & & & $x$ & & \\
\hline 22 & $x$ & & & & $x$ & & \\
\hline 22 & $x$ & & & & & & \\
\hline 23 & $x$ & & & & & & \\
\hline 24 & $x$ & & $x$ & & & $x$ & \\
\hline 25 & $x$ & & & & & & \\
\hline 26 & $x$ & & & & $x$ & & \\
\hline
\end{tabular}

For each turtle the first entry represents results from the surface model; the second entry (if present) is for the water column model. A single entry per turtle indicates a lack of depth data, and hence results are only for the surface model. An ' $x$ ' in the cell indicates a positive linear response to the covariate. Bold turtle IDs are tracks long enough to extend into the putative foraging grounds south of $5^{\circ} \mathrm{S}$.

currents changed the median estimates for distance to patch for 13 turtles with most estimates becoming slightly less negative (Additional file 4: Figures S3.1, S3.2). What this may mean is that in the face of stronger currents, turtles may choose closer patches and not expend as much energy swimming to father patches. For 2 of the turtles $(10,11)$ accounting for currents meant increasingly negative estimates for distance to patch. However these differences in parameter estimates were very minor and the median values fell within the original BCI for this parameter from the model that did not account for currents (in Additional file 4: Figures S3.1, S3.2).

We applied the multiple state model to 6 turtles $(3,4$, $7,8,10$, and 22). The structure of this model included a migratory and foraging state, where all locations south of $5^{\circ} \mathrm{S}$ were considered to be foraging locations [18]. In all cases there was no support for a model that included multiple states, i.e. the $\mathrm{BCI}$ for the $\beta$ parameter for states 
covered 0 (results not shown). This means there was no significant difference in the choices made by the animals in these two states, i.e. they chose patches similarly regardless of location.

Similar to the comparison of the two surface models, when we explore patch choice at depth, we see turtles making different choices about suitability at depth (Table 1, Figure 1). For example, 2 of the turtles express a preference for patches at depth with elevated diatoms (Table 1, Figure 2), and 2 turtles prefer patches with higher mezozooplankton values at depth (Table 1, Figure 2). In contrast, 4 turtles expressed a preference for elevated zooplankton patches at the surface, but not at depth (Table 1, Figure 2).

We plotted the functional response of habitat suitability $h$ across a range of mesozooplankton density (ROMS_zz2) values at the surface and at depth, i.e. in the water column, for several turtles that had significant responses to these covariates. From the results (Figure 3, Figure 4), it was clear that both parameter magnitude and confidence around the estimate were important. For example, turtle 1 and turtle 4 had similar magnitude estimates for the $\beta$ parameter for zooplankton (Figure 3), yet the confidence around that estimate yielded a broader estimate of $h$ for turtle 1 (Figure 3a). Turtle 4 responded to higher levels of mesozooplankton, but with broader confidence limits (Figure 3b). For the results at depth, turtle 4 no longer responded to mesozooplankton (turtles 1

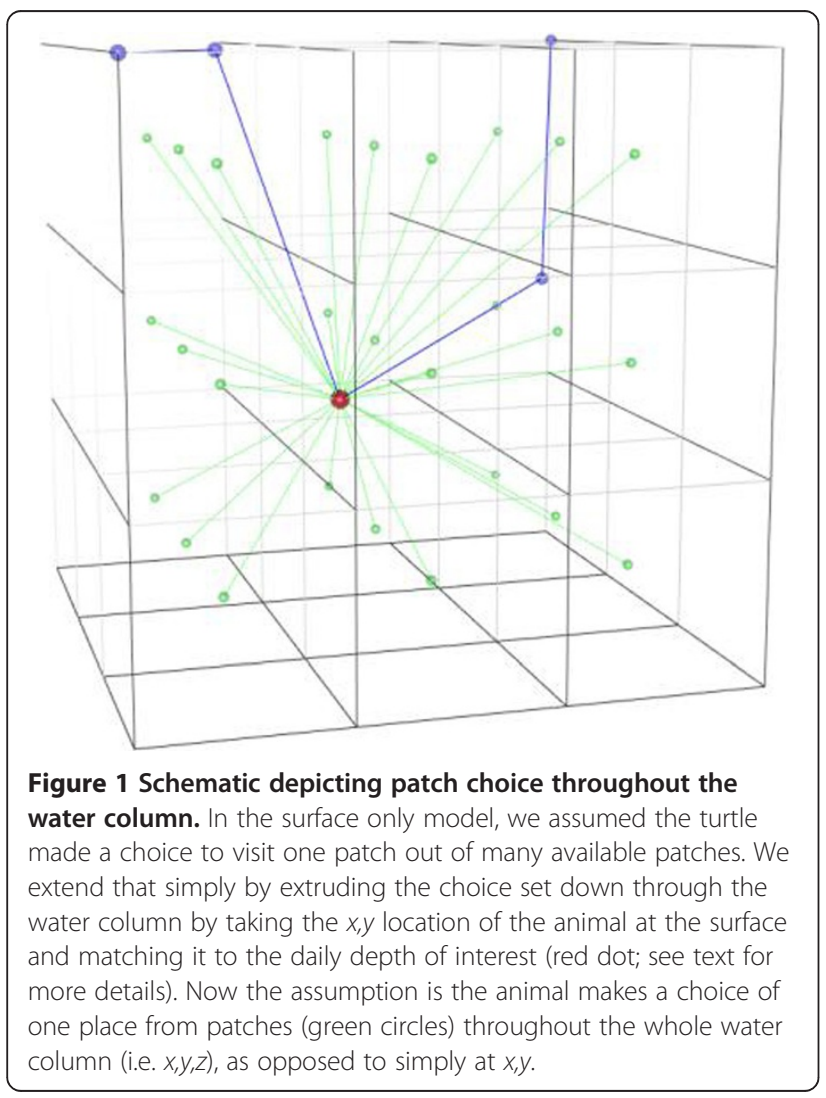

and 26 lacked depth information) (Table 1, Figure 2). In contrast turtles 3 and 8 responded to zooplankton at the surface and at depth (Figure 2, Figure 4). Turtle 8 had a higher median estimate for the $\beta$ parameter for mesozooplankton, but with much broader confidence intervals around the estimate. The functional response for turtle 3 was much narrower than it was for turtle 8 (Figure 2). This means that turtle 3 was preferentially selecting patches at lower levels of mesozooplankton than turtle 8 (Figure 4).

Lastly, results from the sensitivity analysis indicated that as the buffered radius out from the turtle increases, the confidence intervals around $h$ decrease, though increasing radius above $100 \mathrm{~km}$ has little effect on the response (Additional file 5: Figure S2.1).

In this analysis, we have quantified the response of moving turtles to dynamic oceanographic covariates in both 2 and 3 dimensions. This combination informs us about the biology of leatherback turtles, but it also represents a new way to analyse the movement patterns of diving pelagic organisms. One critical finding from the union of the movement model with the ROMSCoSiNE model is how individual turtles are preferentially selecting patches with elevated meso-zooplankton abundance. While it is axiomatic that predators will choose patches with higher prey abundance, this has been difficult to quantify in modeling studies. Here we quantify this relationship across individuals, at the surface, at depth, and in different ocean conditions thereby providing the first quantitative link between movement choices and prey (Table 1, Figure 3). A second critical finding is how our understanding of habitat suitability changes when we look at the surface expression of choice versus the at-depth expression of choice. This is important not only for our understanding of the ecology of leatherbacks, but also for conservation applications. For example, were we to map suitability across a broader spatial extent, the view of this would necessarily change were we to use results from only the surface instead of at depth (Table 1).

The holy grail of many movement studies as well as many habitat modeling studies is to quantitatively link distribution, movement, and abundance of predators to the distribution and abundance of their prey. Because of sampling difficulties, this goal is rarely reached. In the marine realm this linkage is made more difficult by the complexities of the underlying physical template and the scale mismatch between animal movements and covariates - relationships long studied in terrestrial ecology [33-35]. In lieu of testing relationships with prey researchers typically use physical proxies $[28,36]$ to analyse movements in relation to covariates [18,20,30,37]. Our results build upon these efforts by incorporating a dynamic environment and the biology of a moving turtle 


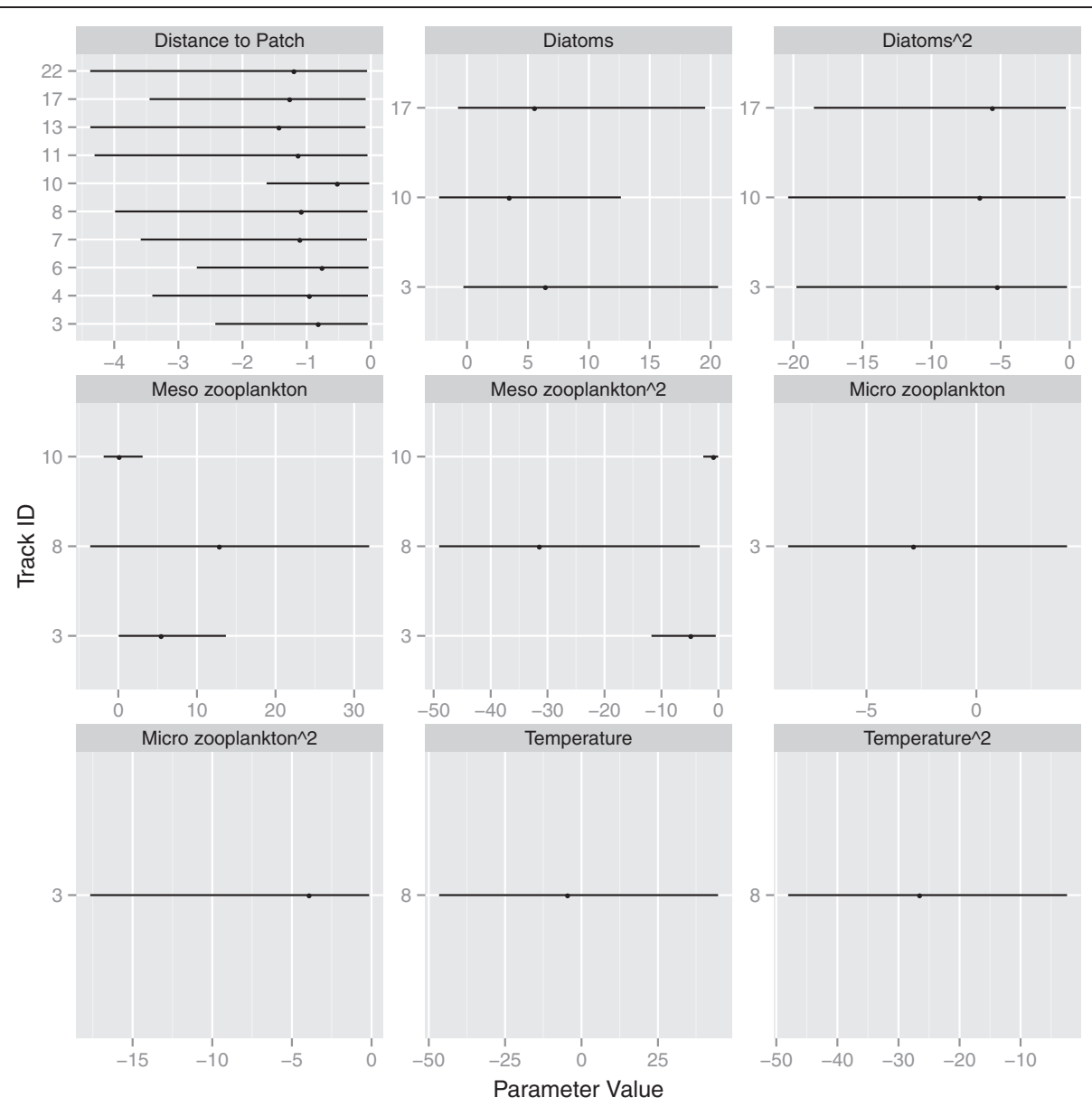

Figure 2 Posterior estimates of each the $\beta$ coefficients governing $h$ for individual turtles from the water column model. Quantitative results for each parameter include the median estimate (50\%) and the 95\% Bayesian Credible Interval (BCI), and are shown with a dot and a line respectively. The covariates were scaled prior to analysis, so the parameters can be compared directly.

into the modeling effort. Instead of visualizing relocations in relation to physical and biological covariates, we can now quantify how the animal responded to them. For example, in two previous papers on the movement of eastern Pacific leatherbacks, movements were characterized as a) being in a migratory corridor $[16,18]$, followed by b) a pelagic foraging ground [18]. We have refined and expanded that view by quantifying the types of patches that Pacific leatherbacks actually exploit - namely closer patches with elevated levels of diatoms and zooplankton. While there is still one more link in the food chain between meso-zooplankton and Pacific leatherbacks, this effort is the closest link yet documented.

While we were able to establish a modeling framework for examining how covariates at depth influence movement of turtles, there are several limitations to our approach. Notably, we cannot know accurately how well the ROMS covariates mimic what is experienced by the animal. It is possible that the model insufficiently represents the sampled environment. Validation of ROMS is well beyond the scope of this paper, but as tagging technology increases in sophistication, in situ information from the tag can be used to validate predictions from the ROMS model. There are also potential issues with the co-variation in some of the ROMS variables, i.e. diatoms are correlated with zooplankton (Additional file 6). One possible way to address this would be variable reduction with a principal components analysis. Next, we do not account for error in the sampled variables. Foster et al. [38] have shown that failure to account for error in variables can lead to bias in parameter estimates and false confidence in the uncertainty of the estimates. While their approach was slightly different from ours, i.e. our biological and physical covariates come from the same source, this is an important issue that should be addressed in future applications. Also, as noted in the methods, the resolution of the depth data from the tag is very limited. An interesting test of this would be to first apply the model to a more finely resolved track and then coarsen it to the depth-bin data used here and compare 


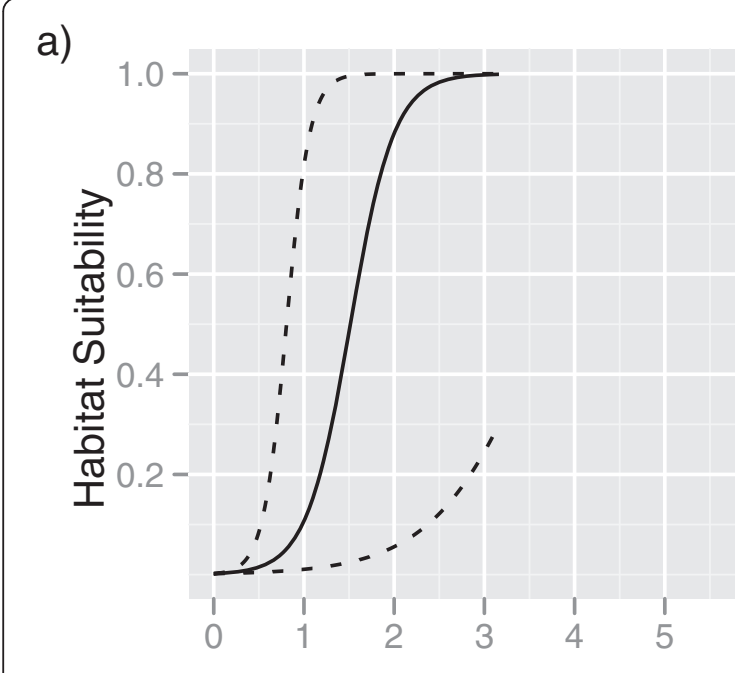

b)

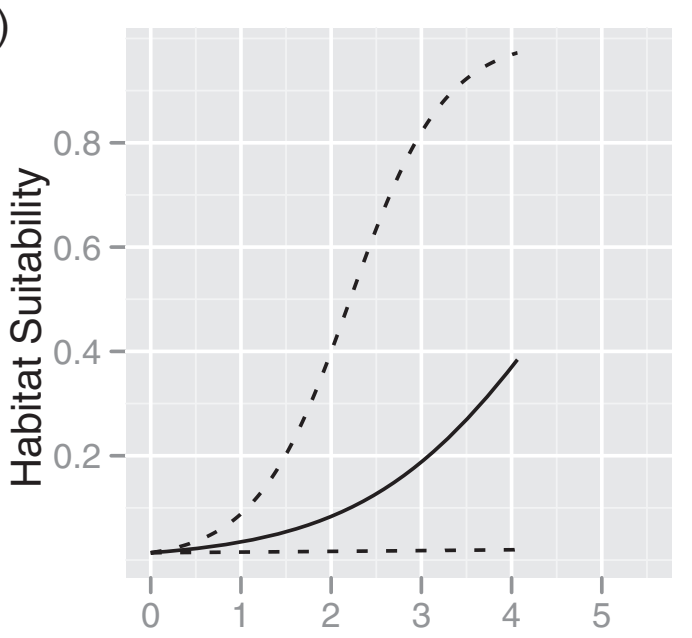

c)

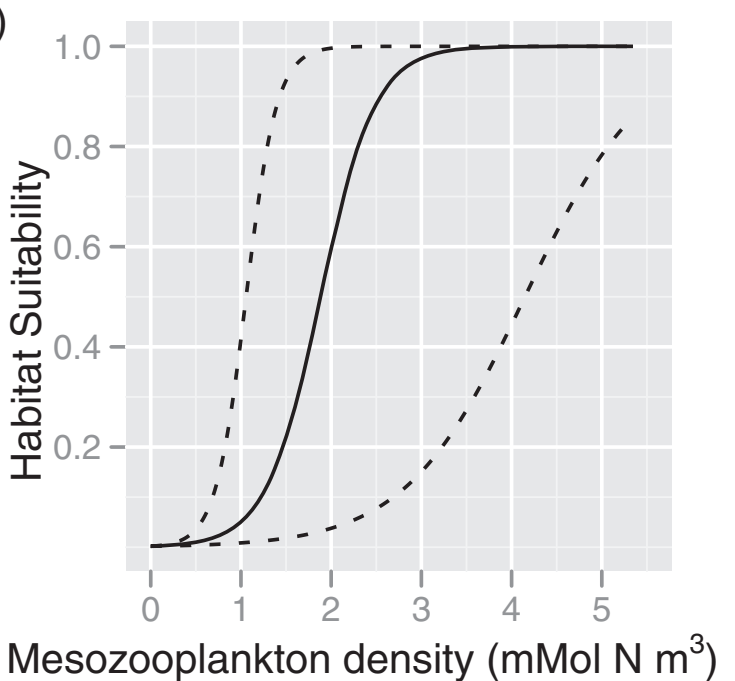

Figure 3 Habitat suitability in relation to mesozooplankton (ROMS_zz2) at the surface for three different turtles $(a, 4 ; b, 26 ; c, 1)$. Thick black line represents the median response, dashed lines represent the uncertainty in the parameter estimate. See text for details on the computation of habitat suitability.

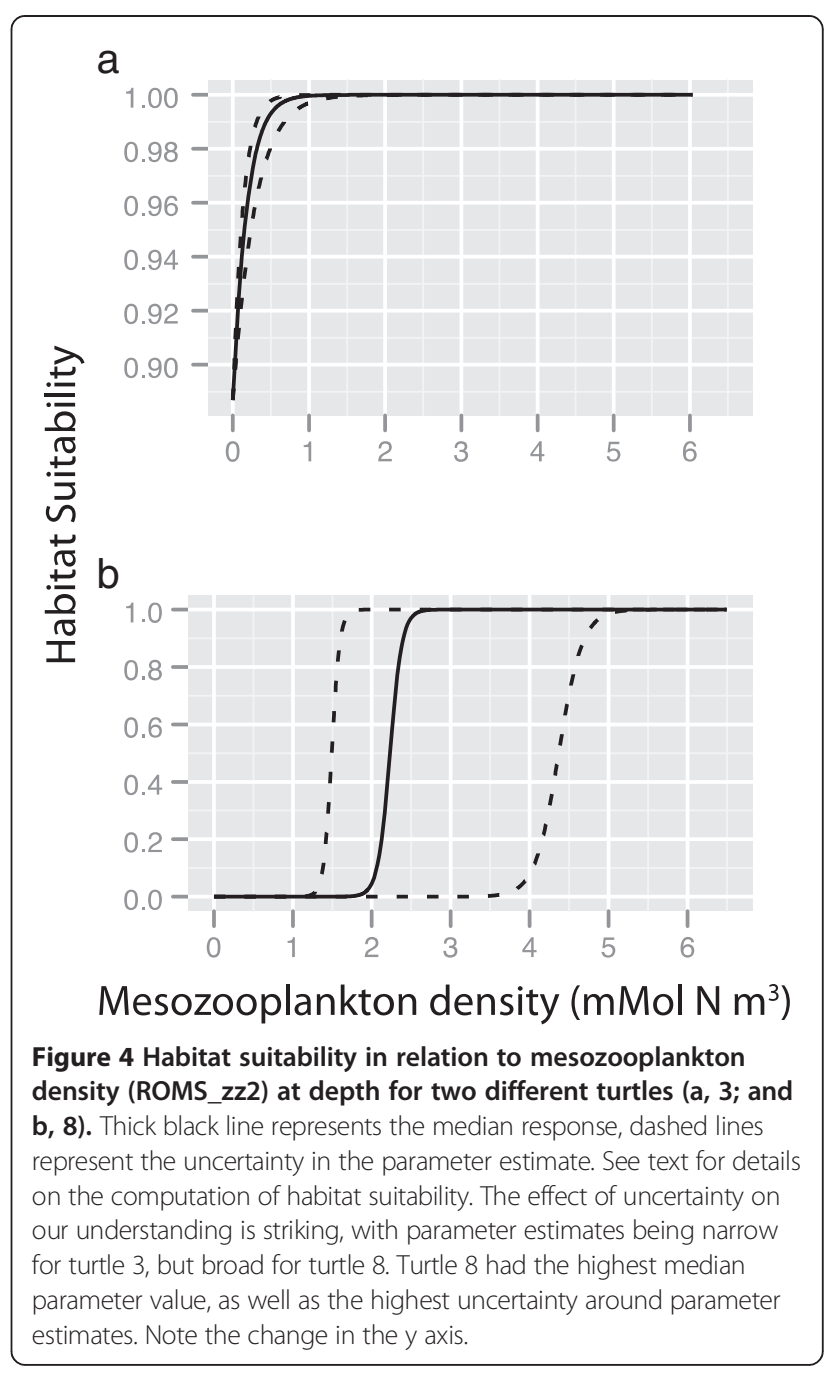

the results. Finally, we do not include formal model selection herein. This is in part because this represents an initial approach to analyse movement data in conjunction with covariates at depth, but also, because of the high dimensionality of the data, a procedure such as RJMCMC would be computationally extremely demanding. Though we have developed the Gibbs Sampler in R (See Additional file 1), we are working on recasting it within BUGS to incorporate recent model selection tools like the LASSO [39] and Elastic Net [40]. See Rockova et al. [41] for a recent review of these methods in a Bayesian model selection framework. Because of the myriad of limitations to the analysis, we caution that inference at this point is more descriptive rather than causal. Model complexity itself is a limitation, which makes it difficult to run and test many scenarios quickly. As we address these limitations, our understanding of what drives the biology should increase.

One interesting result was the overall lack of quantitative relationship between temperature and patch choice 
(Table 1, Figure 3, in Additional file 4: Figure S3.1, S3.2). Based on the previous tagging study of Pacific leatherbacks $[18,21]$, we expected to see turtles occupying specific thermal niches. It is possible that this is a data limitation. As compared to Shillinger et al. [18,21], we had fewer tracks to analyze and both the diving and relocation data were at a lower spatial and temporal resolution. More importantly, we had fewer tracks that extended into the putative foraging grounds, and it is possible that the animals make more specific choices about suitable patches when foraging, then when migrating. While we did not see support for a model that included states, it is possible that with more data such distinctions could emerge.

Another interesting result was the relatively weak influence of the currents. While we did document an effect of currents on the distance to patch parameter (Additional file 4: Figures S3.1, S3.2), these effects were very small. These small differences are likely due to the large differences in mean velocity of the turtles $(0.37 \mathrm{~m} / \mathrm{s})$ as compared to the mean velocity of the currents, e.g. $-0.01 \mathrm{~m} / \mathrm{s}$ for the N-S current. That is, in comparison to the speed of the turtle, the speed of the current at the surface is relatively minor - hence the lack of a strong effect. For the two turtles for whom the distance to patch parameter became more negative, i.e. they chose farther patches, both of these animals appeared to enter and then also exit the putative foraging grounds. Though we did not find support for a multi-state model, it does appear visually that these animals are experiencing different current regimes before, during, and after the time spent in the foraging ground. Further work with a pared down model including just the distance to patch covariate may offer insight.

Earlier biologging technology placed limits on the transmission of depth data from a diving animal [42]. Because of this, researchers have typically focused on the displacements in $x, y$ and either ignored diving behavior or have done post-hoc analysis of the diving data [30,37]. With the advent of higher resolution tags, researchers can reconstruct more complex analyses [4]. In seals, for example, recent studies have documented the importance of understanding at-depth behaviour $[2,3]$. However, even with these tags, interfacing the dive profile with the environment is difficult (though see Bestley et al. [5] and McClintock et al. [6] for initial attempts at using information at depth to inform state estimation). Despite this difficulty, behavior at depth is crucial for a broader understanding of leatherback movements because leatherbacks are primarily diving animals [24,42-45]. Our results suggest that the interpretation of movement behavior at the surface is quite different from what takes place at depth. The data analyzed here were limited as well, in that we did not have the full diving record for each animal, and were forced to analyze use of depth bins, as opposed to specific depths. We surmise that with added resolution through the water column, the differences in $h$ that we observed would be even greater.

For most of the turtles on which we analysed surface and depth data, the significant covariates at the surface are no longer significant at depth (Table 1). Of the 6 turtles that had significant responses to zooplankton at the surface, only 2 also had a significant response at depth (Table 1). Conversely, 3 turtles did not respond to zooplankton at the surface, but did at depth (Table 1). Though conservation decisions are often made based on distribution on the surface of the ocean, i.e. establishing a management area or MPA, we argue that from a biological perspective the covariates that diving animals respond to the surface may not be indicative of their behavior at depth. Mapping out habitat volumes in $x, y$ and $z$ space may offer a more robust picture of the environments that leatherbacks prefer.

Careful reading of the differences in the surface and depth models indicates the turtles appear to be responding to fewer variables at depth than at the surface (Table 1). One possible explanation is that gradients in $z$ may be more important than the variable itself. For example, the presence of the thermocline or halocline at depth (Eckert [24]) might be a patterning variable for jellyfish, and hence a feature that turtles respond to rather than just temperature itself. In addition to the change of a variable through the $z$ dimension, it is also possible that animals respond to an integration of values through the water column [46]. Another possible explanation is that pelagic foraging Eastern Pacific leatherbacks are in fact finding fewer prey items and foraging less successfully [19]. Finally, the majority of tracks that extend into the putative foraging region were during an El Niño year (Figure 5), and it is probable that this was a poor foraging year. It has been shown that El Niño events result in lower reproduction in EP leatherbacks [47-49], and it is therefore likely that a poorer prey environment would result in a weaker correlation between prey and movement choice as shown here.

\section{Conclusions}

We have fitted a model of animal movement to the movement tracks of individual Pacific leatherback turtles. Through this process we have integrated covariates from a dynamic ocean model in an effort to quantify how animals make choices about the suitability of habitat patches. The results build upon other modeling efforts in three important ways: 1) as opposed to movement phenomena, e.g. step lengths and turning angles, we exploit movement choices in the likelihood; 2) those choices are conditioned upon the present location of an 


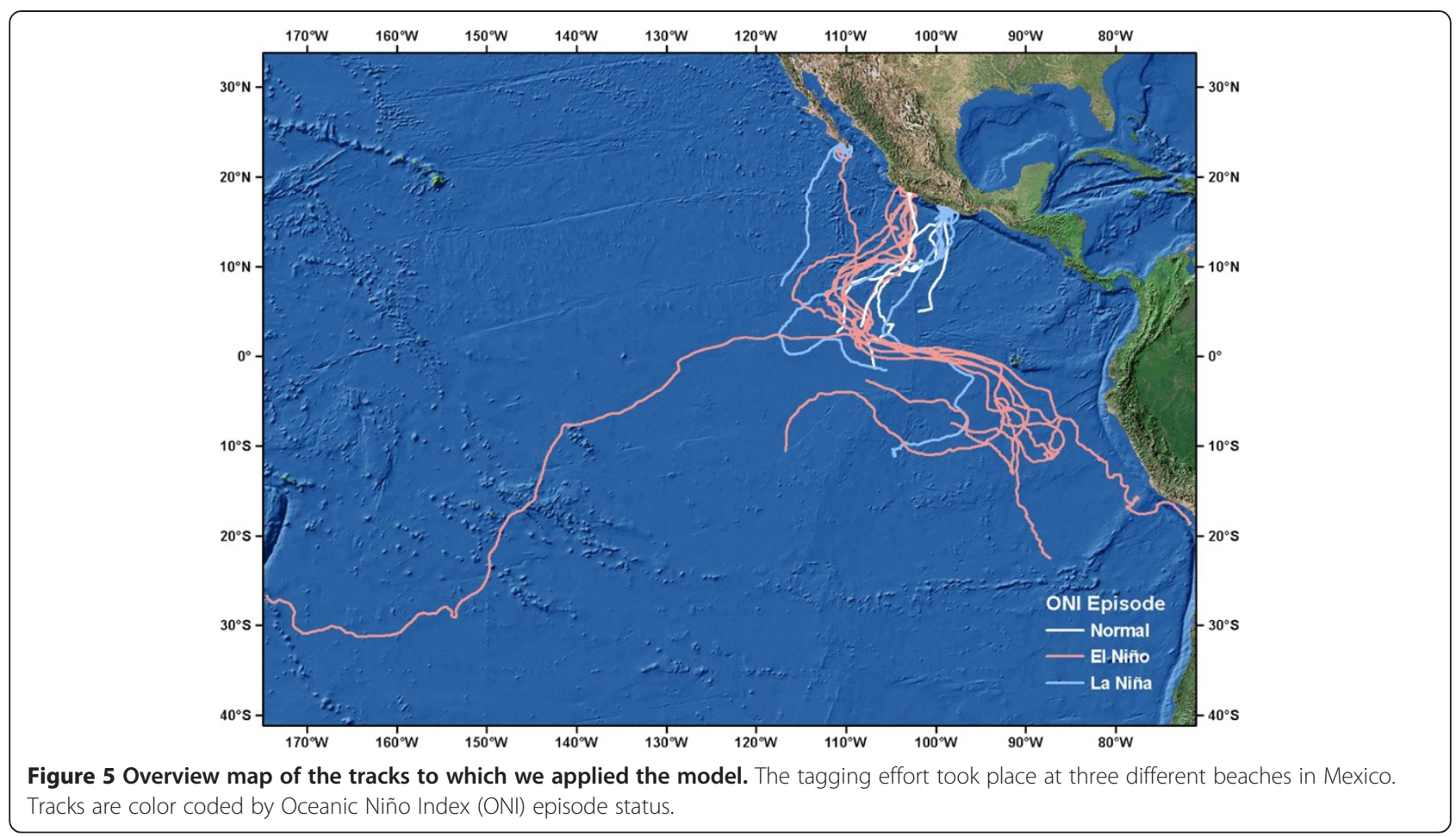

individual, and suitability of a patch comprised of dynamic covariates; and 3) we quantify how these processes play out at depth. By quantifying these processes we can begin to map out the types of environments diving animals prefer, and we can use this as a basis for further inference on overlaps in space and time between turtles and fishing activity. In addition, we can conceptualize and map these overlaps in the water column, which will provide important future baselines for the protection of this critically endangered species.

\section{Methods}

\section{Data summary - turtles}

Twenty-six turtles were tagged at three different beaches along the Pacific coast of Mexico (Table 2, Figure 5). Broadly speaking after the nesting period, the turtles left these nesting areas and headed out into the ocean along a SW migration route. These migratory movements are consistent with those of leatherbacks leaving nesting beaches in Playa Grande, Costa Rica [16,18]. Most turtles explore a wide-ranging pelagic area, while one follows a coastal route, and one ranges directly almost to New Zealand (Figure 5). (A full summary and description of the tagging effort, and some of these data can be seen in Eckert and Sarti [17].) The tracks were irregularly spaced in time and observed with error. To adjust for this, we fit a state-space model to the data to provide regular estimates of true location [32]. We then used these daily estimates of location to estimate habitat suitability for each animal.
Because the turtles were instrumented for movement as well as basic diving information, we were able to explore the relationship to environmental features both at the surface and at depth (see Data Structures section below). Of the 26 total tracks, we deemed 15 sufficiently long for analysis, i.e. the tracks were longer than 45 days. In addition, we removed one track from the analysis (\#18), as it appeared to have died during its post-nesting migration. The mean dive depth for all turtles was $34.09 \mathrm{~m}$; mean maximum dive depth was $123.9 \mathrm{~m}$.

Additional file 4: Figure S3.1 depicts the temporal extent of the tracks in conjunction with the start/stop times of the El Niño/La Niña events (beginning and ending dates of each episode taken from the Oceanic Niño Index (ONI) computed from ERSST.v3 anomalies; see http://www.cpc.ncep.noaa.gov/products/analysis_monitoring/ensostuff/ensoyears.shtml). Of the 15 tracks, 4 were in "normal" years, 8 were in El Niño years, and 3 were in La Niña years (Figure 5, Additional file 4: Figure S3.1).

\section{Data summary - environmental variables}

Many studies have investigated the environmental conditions encountered by migrating marine turtles by spatiotemporally intersecting the turtles' tracks with time-series maps of oceanographic parameters sensed remotely by satellites [14]. Because such remotely sampled data are limited to oceanic surface features, we sampled physical and biological explanatory variables from ROMS-CoSiNE, a 4-dimensional biophysical simulation of the Pacific 
Table 2 Summary Data for turtle movement tracks from three nesting beaches in Mexico

\begin{tabular}{|c|c|c|c|c|c|c|}
\hline TrackID & Year & Beach & Locations & Distance $(\mathbf{k m})$ & Included & Reason \\
\hline 1 & 1993 & Mexiquillo & 52 & 2,448 & Yes & \\
\hline 2 & 1993 & Mexiquillo & 8 & 497 & No & locations \\
\hline 3 & 1997 & Mexiquillo & 298 & 9,425 & Yes & \\
\hline 4 & 1997 & Mexiquillo & 234 & 8,177 & Yes & \\
\hline 5 & 1997 & Mexiquillo & 1 & 426 & No & locations \\
\hline 6 & 1997 & Mexiquillo & 118 & 4,756 & Yes & \\
\hline 7 & 1997 & Mexiquillo & 266 & 9,001 & Yes & \\
\hline 8 & 1997 & Mexiquillo & 286 & 8,304 & Yes & \\
\hline 9 & 1997 & Mexiquillo & 46 & 329 & No & locations \\
\hline 10 & 1997 & Mexiquillo & 298 & 10,535 & Yes & \\
\hline 11 & 1997 & Mexiquillo & 436 & 13,097 & Yes & \\
\hline 12 & 1997 & Mexiquillo & 0 & 664 & No & locations \\
\hline 13 & 1999 & Cauhitan & 124 & 4,975 & Yes & \\
\hline 14 & 1999 & Cauhitan & 0 & 215 & No & locations \\
\hline 15 & 1999 & Cauhitan & 0 & 444 & No & locations \\
\hline 16 & 2000 & Agua Blanca & 53 & 3,178 & Yes & \\
\hline 17 & 2000 & Cauhitan & 21 & 1,892 & No & locations \\
\hline 18 & 2000 & Cauhitan & 279 & 12,244 & No & Turtle is dead \\
\hline 19 & 2000 & Cauhitan & 42 & 1,197 & No & locations \\
\hline 20 & 2000 & Cauhitan & 1 & 207 & No & locations \\
\hline 21 & 2000 & Cauhitan & 26 & 1,309 & No & locations \\
\hline 22 & 2000 & Cauhitan & 468 & 12,828 & Yes & \\
\hline 23 & 2001 & Cauhitan & 32 & 1,532 & Yes & \\
\hline 24 & 2001 & Cauhitan & 196 & 9,000 & Yes & \\
\hline 25 & 2001 & Cauhitan & 97 & 2,961 & Yes & \\
\hline 26 & 2003 & Agua Blanca & 79 & 4,022 & Yes & \\
\hline
\end{tabular}

Included are the number of post-nesting locations, and the cumulative distance for the entire track. Turtles excluded from the modeling analysis are noted, along with the reason for exclusion. In the Reasons column, locations meant there were too few post-internesting locations.

Ocean that couples the Carbon, $\mathrm{Si}(\mathrm{OH}) 4$, Nitrogen Ecosystem model (CoSiNE; Figure S1.1) [50,51] to the Regional Ocean Modeling System (ROMS) [52]. We used four physical variables and four biological variables from ROMS-CoSiNE: temperature, salinity, N-S current velocity, E-W current velocity, phytoplankton density, diatom density, micro-zooplankton density, and mesozooplankton density (Additional file 6: Table S1.1, Figure S1.3). To ensure independence of the predictor variables, we calculated correlation and covariance values in the ROMS covariates and found limited correlation among the variables (Additional file 6: Tables S1.2, S1.3). The highest correlations and covariances were between the diatom variables and the zooplankton variables, though this is to be expected from the model structure (Additional file 6: Figure S1.1). For further details on both the ROMS-CoSiNE model and the extraction of covariates, see Additional file 6.

\section{Modeling summary}

The principle behind our modeling approach was to evaluate choices that the moving animal made in reference to choices the animal could have made. The approach may be thought of as a resource selection function embedded within a movement model. Because we first fit a state-space model to the locations, an alternative way of viewing the model is as a discrete choice model conditioned upon known locations. That is, the animal makes choices about different patches in an attempt to satisfy or maximize some criteria [53]. At a given time $t$ we observe an animal's location, and we determine the values of environmental covariates at these same location. It is plausible that the animal chose this location from among several locations that was available to it, i.e. within some perceptual range. By determining the values of covariates at those patches, we then quantitatively assess what was unique about the 
visited patches. Unlike a simple resource selection function, we assume that the selection of future patches is conditioned upon the animal's present location. By making the choices spatially and temporally conditional, we make inference on the choices the animal makes as it moves. Because we have depth information, we can also explore the choice of a patch at depth from several candidate patches throughout the water column. The surface view corresponds to a pixel-based view, while the depth view corresponds to a voxel-based view (Figure 1). Figure 1 provides a conceptual model. The blue line represents the track of a diving turtle. The red dot is the patch (or voxel) the animal chose; the green dots represent the candidate patches (voxels).

Following [12] we can express this mathematically as follows. The event that an individual $i$ at time $t-1$ moves from location $j$ to $k$ at time $t$ is given by:

$$
z_{i j k, t-1}=I\left(s_{i, t-1}=j, s_{i, t}=k\right)
$$

The indicator function $I()$ is 1 when true, and 0 otherwise, and $s_{i, t}=k$ is the time specific location $k$ of individual $i$ on the map, i.e. a two dimensional set of Cartesian coordinates. The location $k$ is chosen from the set of potential choices $k_{i, t}=\left\{1, \ldots, K_{i, t}\right\}$. This set of potential choices is determined spatially by buffering out from the animal to a radius equal to the maximum daily distance the animal travels. For the turtles in our study, this maximum distance was recalculated to include the effect of oceanic currents. Specifically we subtracted the N-S and $\mathrm{E}-\mathrm{W}$ component of the current from each $x, y$ location of a candidate patch (Figure 6). The observed move $Z_{i j k, t-1}$ by the individual is from location $s_{i, t-1}=j$ to $s_{i, t}=k$. This movement event from $j$ to $k$ has probability distribution:

$$
\operatorname{Pr}\left[Z_{i j k, t}\right]=\operatorname{Multinom}\left(1, \theta_{j k, t-1}\right),
$$

where $\theta_{j k, t-1}$ is the length- $K_{i, t}$ vector of probabilities. The probability $\theta$ describes $h$, which is the relative habitat suitability of the chosen patch:

$$
\theta_{j k, t-1}=\frac{h_{j k, t-1}}{\sum_{k \in K_{i, t}} h_{j k, t-1}}
$$

The relative suitability $h$ of location $k$ is conditioned upon individual $i$ being in location $j$ at time $t-1$, and is a function of covariates, $\operatorname{logit}\left(h_{j k, t-1}\right)=\mathrm{X}_{j k, t-1} \beta$. This parameter is conceptually similar to the utility $U$ parameter in discrete choice models [53]. The parameter $h$ must be positive, but does not have to saturate at 1 . We chose a logit to concentrate the effects in the mid-range. Other functional forms could be used. The design matrix describes the covariates of choice $k$ relative to an individual who is located at $j$ at time $t-1$, and $\beta$ describes the parameters for individual covariates, i.e.,

$$
X_{j k, t-1} \beta=x_{1, j k, t-1} \beta_{1}+x_{2, j k, t-1} \beta_{2}+\cdots x+x_{p, j k, t-1} \beta_{p}
$$
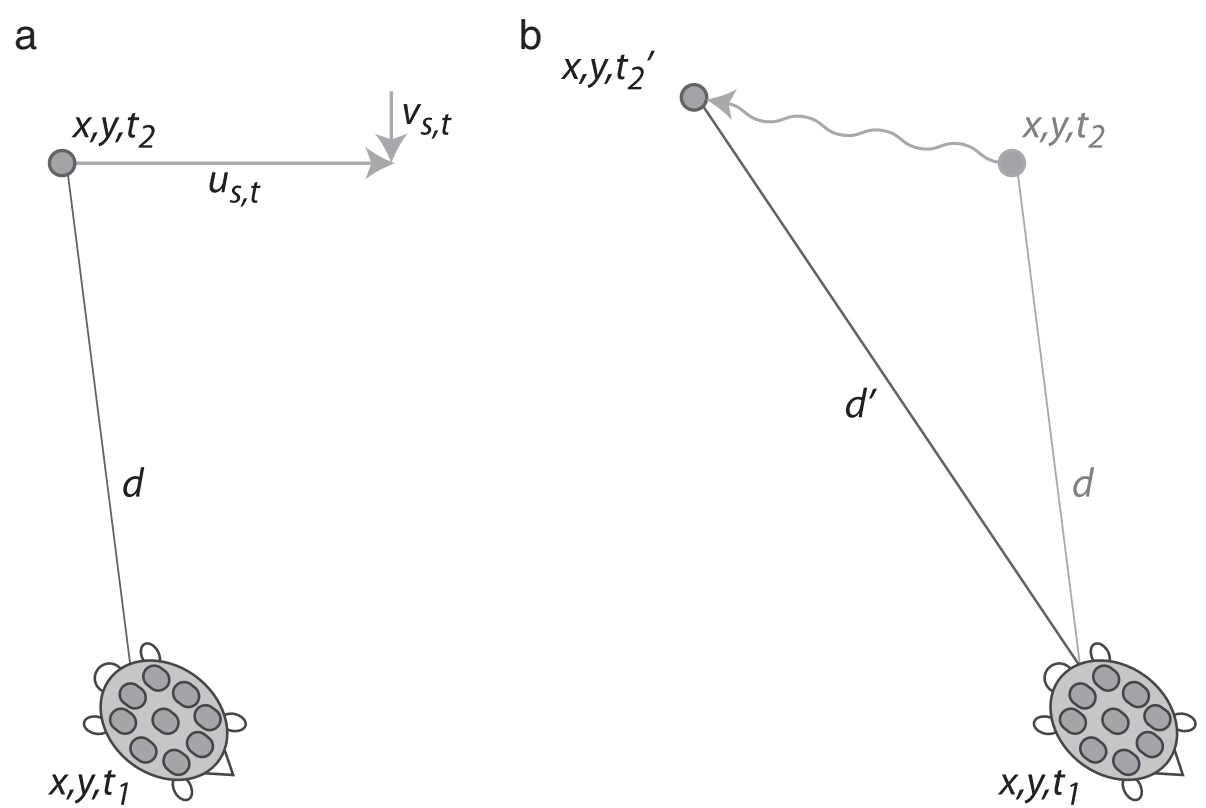

Figure 6 Schematic figure of our method for incorporating the effect of currents on distance between patches. Panel a depicts the turtle at time 1 and a candidate patch at time 2. Distance $d$ is the Euclidean distance separating the patches. The light grey lines depict the N-S surface current vector $\left(v_{s, t}\right)$, and the E-W current vector $\left(u_{s, t}\right)$. Panel $\mathbf{b}$ depicts the new position of the candidate patch after the currents have been subtracted; distance $d^{\prime}$ reflects the new distance between the turtle and the patch after currents have been accounted for. 
where $x_{j k, t-1}$ is a length $p$ row vector of covariates, $\beta$ is a length $p$ column vector. The model summary is as follows:

$$
p\left(\beta \mid \mathrm{z}_{i j, t}, x_{j k, t}\right) \propto \prod_{i=1}^{n} \prod_{t=2}^{T_{i}} \text { multinom }\left(z_{i j, t} \mid 1, \theta_{j k, t-1}\right) N_{p}(\beta \mid 0, V),
$$

where $z$ are the observed locations of the animal. For the priors we use non-informative truncated multivariate normal distributions for centered on zero with large variance, $V$. This formulation takes us from the observed data (locations, unique values of covariates) to inference about a hidden process - the response of a moving turtle to a dynamic environment.

\section{Data structures}

To fit this model to data (See Additional files 1, 2, and 3 for the $\mathrm{R}$ code), we need two data structures [13]. The first was the movement track itself with the values for the covariates of interest extracted at each location. This was accomplished with the MGET toolbox [54] in ArcGIS ${ }^{\ominus}$ The second data structure was a ragged array comprised of available patches and their environmental input values surrounding each unique location in the track. To build this we used a combination of custom Python code and the MGET tool box. At each location, we buffered out a fixed circular radius of $100 \mathrm{~km}$ (see below), and within that area we sampled inputs at the centroid of each cell. We extracted the unique values of inputs from the ROMS-CoSiNE model for each of these sampling areas, and built up the data structure for the remainder of the track. We use 'input' to refer to specific variables in the ROMS-CoSiNE model; following extraction of the inputs we will turn these into covariates. For example, salinity is an input to the data structure; for use in the model we create linear and quadratic covariates from this input. The juxtaposition of these two data structures can be visualized as a ribbon plot that highlights the values perceived and the values chosen by the animal along its track (Figure S1.4) within the buffered range. In addition to the inputs from the oceanographic model, we calculated the distance to each patch from the animal's present location. To do this, we calculated the distance from an animal's location at time $t$ - 1 to the location of all patches available at time $t$. (For further details on the extraction of ROMS-CoSiNE variables, consult Additional file 6). The environmental covariates were standardized using the scale function in $\mathrm{R}$ [55].

We chose the initial radius for the buffer around each point by determining the maximum daily distance for all turtles, which was $168 \mathrm{~km}$. We then set the buffer distance to $200 \mathrm{~km}$ (radius $=100 \mathrm{~km}$ ) to encompass this maximum distance. While ROMS-CoSINE has a nominal pixel dimensions of $13.8 \times 13.8 \mathrm{~km}$, we sampled at approximately a $4 \mathrm{~km}$ resolution. This resolution was chosen during the exploratory phase of the analysis when we used remotely sensed sea surface temperature images. For the surface only model runs, the average number of candidate patches for each location within this distance was 633. In the water column model, there were 7 unique depth layers $(6-12 \mathrm{~m}, 12-51 \mathrm{~m}, 51-78 \mathrm{~m}$, 78-102 m, 102-150 m, 150-201 m, > $201 \mathrm{~m})$. These depth layers correspond to the bins in which the depth of each dive of the turtle lies. Because of data transmission limitations in the ARGOS system, that means actual depth of each dive is only known to occur in one of these 7 depth layers. In each of these depth layers, we extracted input values with the $x, y$ locations that corresponded to the $x, y$ locations of the candidate patches at the surface. Accordingly for the model runs that compared selected patches through the water column the average number of patches within this distance and through the water column was 4,494. We also explored the sensitivity of model results to our assumptions about the perceptual distance in two ways. First, for one representative turtle (\#11), we ran the model with four increasing buffer limits $(50 \mathrm{~km}, 100 \mathrm{~km}, 150 \mathrm{~km}$, and $200 \mathrm{~km}$ ). The sensitivity of the results to buffer size was quantitatively examined by using posterior estimates of the $\beta$ to plot normalized habitat suitability for each of the environmental inputs. Exploring the sensitivity in this way allowed us to determine how the definition of "available" affects our inference on the turtle's choices.

\section{Model application to data}

We fit the model to location data for each individual. The $\mathrm{R}$ code we wrote for the Gibbs Sampler and all helper functions is given in Additional files 1, 2, and 3. We initialized each chain with parameter values close to 0 , and within a Gibbs sampling framework [56], we then proposed and accepted/rejected values for these parameters. We proposed from a truncated multivariate normal distribution (see Additional file 3 for the function); we chose a truncated normal to efficiently propose parameter values for which we assumed a positive or negative relationship. We assumed a functional form for the response of the animals to the oceanographic inputs, namely an envelope shaped response that assumes there are some intermediate values of each input the animal prefers. Accordingly we had both a linear and quadratic $\beta$ term to estimate for each of the oceanographic inputs. These are the covariates used in the model. Further, using the truncated multivariate normal, we could propose positive values for the linear terms, and negative values for the quadratic terms. We accepted these proposed values using a Metropolis step. We derived and used an empirical covariance matrix for this multivariate distribution. Starting with a default covariance matrix (on-diagonal values $=10$ ), we then calculated and 
employed the empirical covariance matrix after 1,000, and 100,000 steps through the Gibbs sampler. We used uninformative flat priors centered on 0 with large variance, and ran the Gibbs sampler for 250,000 steps, saving the thinned last 150,000 values. Convergence of each chain was assessed visually, and using diagnostic criteria from the superdiag package [57]. Judging by the Geweke metric [58], convergence was reached for each of the variables (Additional file 7).

With these thinned chains, we derived posterior estimates of the $\beta$ values that govern habitat suitability, $h$. We calculated a global $h$ for any given covariate by holding all other covariates fixed at their median value, and calculating the inverse logit of [13]. We plotted $h$ over the range of each individual covariate to visualize how the turtle makes choices for ranges of a given covariate conditioned upon all the remaining covariates. Because this analysis is Bayesian, we integrated over the estimates of each parameter to visually depict how uncertainty in the parameter estimates affects our understanding of the hidden process $h$.

We fit four different models to the individual movement tracks. The first model, hereafter the "surface" model, was the baseline model to infer how animals make choices in relation to habitat suitability comprised of 7 environmental inputs. The second model, hereafter the "surface with currents" model, accounted for the role of ocean currents on locations of the individual turtles. We did this by altering how the distance to patch covariate was calculated. In the surface model the distance between an animal's location at time $t-1$ to all possible locations at $t$ was calculated using straight Euclidean distance. In the second, or "surface with currents" model we assumed the same location at $t-1$, but now subtracted the N-S and E-W current vectors to each of the possible locations at $t$ (Figure 6). Note that we only used surface currents in this correction, i.e. we ignored currents at depth. We assume that the location of the turtle, as reported by the satellite, accounts for the many factors influencing turtle movement - including currents. This allowed us to calculate the distance a turtle would have to swim from its location to a patch unaffected by currents. (Note that Figure 6 is exaggerated for display purposes; the actual distances and displacements are quite small in relation to the turtle's movements.) The third model, hereafter the "multiple state" model included the effect of currents and an a priori estimate of behavioral states comprised of migratory and foraging states. The geographic split between these two areas was initialized at $5^{\circ} \mathrm{S}$ [18]. The tracks from only six turtles extended into the putative foraging grounds. The fourth and final model, hereafter the "water column with currents" model, differed from the surface model by accounting for patch choices made through the water column, i.e. instead of constraining future locations to those in the $x, y$ plane, we incorporated depth information from the tag to infer patches chosen throughout the water column (Figure 1). To fit this model to data, we first specified a "full" model with all covariates included. We then determined the covariates that were significant, i.e. non-zero estimates for the $\beta$ parameters, and then re-fitted a "final" smaller model.

In summary, outputs from the model allow us to quantitatively determine the preferred range of covariate values for individual turtles, accounting for location, distance to patch, both at surface and throughout the water column. This latter perspective (depth) is particularly important to include, because of the oceanic, deep diving nature of the leatherback and because quantifying the linkage because water column covariates and leatherback movements has not been achieved.

\section{Availability of Supporting Data}

The data used in this analysis will be available shortly on OBIS-SEAMAP (http://seamap.env.duke.edu/).

\section{Additional files}

Additional file 1: Knitr document providing a tutorial on the Gibbs
sampler used in the manuscript. The PDF includes all of the code
written and used - including helper functions. In addition, it includes the
results from a model fit to one track.
Additional file 2: Full R code to fit the model outlined in Additional
file 4 .
Additional file 3: Helper functions needed by the main R code.
Additional file 4: Graphical results from additional models
considered.
Additional file 5: Results from the sensitivity analysis for the effect
of perceptual range.
Additional file 6: Supplemental material describing specifics of the
covariate sampling from the 4D oceanographic model.
Additional file 7: Convergence diagnostics for the MCMC chains for
each environmental covariate.

Competing interests

The authors declare that they have no competing interest.

\section{Authors' contributions}

RSS conducted the analysis, summarized data, and wrote the manuscript. JJR conducted the data extraction, and built the software linking ArcGIS to the ROMS Model. SE collected the data, and provided biological expertise. HB fit the state-space model code to data. PNH helped with experimental design and analysis. FC and LS contributed the ROMS Model, and facilitated software linkages. JSC wrote the Gibbs sampler, and helped with analysis. All authors read and approved the final manuscript.

\section{Acknowledgements}

We thank Laura Sarti Martínez, Ana R. Barragán, Gerald Kooyman, Paul Ponganis and Peter Dutton as co-investigators in the collection of the leatherback tracking data. We thank Rachael Brady for helpful comments on the figures, and we thank Ben Best for help creating Figure 1. Andre Boustany and Ben Best provided constructive criticism on an earlier version of this manuscript. We also thank James Spotila for his leadership in assembling the Pacific Leatherback satellite telemetry team that provided valuable suggestions and insight into our telemetry data. Finally we 
acknowledge the financial support of DeMets Candy Company, the U.S. National Marine Fisheries Service, Scripps Institute of Oceanography, the Universidad Nacional Autónoma de México and the Wider Caribbean Sea Turtle Conservation Network in supporting the tracking of leatherback on this project. We thank the Lenfest Oceans Program for the financial support that enabled the analysis that resulted in this manuscript. Lastly, we thank Simon Benhamou and two anonymous reviewers whose comments considerably strengthened this manuscript.

\section{Author details}

${ }^{1}$ Nicholas School of the Environment and Earth Sciences, Duke University, Durham, NC 27708, USA. ${ }^{2}$ Centre for Research into Ecological and 808 Environmental Modelling, The Observatory Buchanan Gardens, University of St. Andrews, St. Andrews, Fife KY16 9LZ, Scotland, UK. ${ }^{3}$ Wider Caribbean Sea Turtle Conservation Network (WIDECAST), 1348 Rusticview Drive, Ballwin, MO 63011, USA. ${ }^{4}$ Department of Biology and Natural Resources, Principia College, Elsah, IL 62028, USA. ${ }^{5}$ Chesapeake Biological Laboratory, University of Maryland, Solomons, MD 20688, USA. ${ }^{6}$ School of Marine Sciences, University of Maine, Orono, ME 04469, USA

Received: 30 November 2012 Accepted: 30 October 2013

Published: 20 November 2013

\section{References}

1. Bailleul F, Pinaud D, Hindell M, Charrassin JBI, Guinet C: Assessment of scale-dependent foraging behaviour in southern elephant seals incorporating the vertical dimension: a development of the First Passage Time method. J Anim Ecol 2008, 77:948-957.

2. Thums M, Bradshaw CJA, Hindell MA: In situ measures of foraging success and prey encounter reveal marine habitat-dependent search strategies. Ecology 2011, 92:1258-1270.

3. Austin D, Bowen WD, McMillan Jl, Iverson SJ: Linking movement, diving, and habitat to foraging success in a large marine predator. Ecology 2006, 87:3095-3108

4. Biuw M, Boehme L, Guinet $C$, Hindell $M$, Costa D, Charrassin JB, Roquet F, Bailleul F, Meredith M, Thorpe S, Tremblay Y, McDonald B, Park Y-H, Rintoul SR, Bindoff N, Goebel M, Crocker D, Lovell P, Nicholson J, Monks F, Fedak MA: Variations in behavior and condition of a Southern Ocean top predator in relation to in situ oceanographic conditions. Proc Natl Acad Sci 2007, 104:13705-13710.

5. Bestley S, Jonsen ID, Hindell MA, Guinet C, Charrassin J-B: Integrative modelling of animal movement: incorporating in situ habitat and behavioural information for a migratory marine predator. Proc $R$ SOC $B$ Biol Sci 2012, 280:20122262.

6. McClintock BM, Russell DJ, Matthiopoulos J, King R: Combining individual animal movement and ancillary biotelemetry data to investigate population-level activity budgets. Ecology 2013, 94:838-849.

7. Le Boeuf BJ, Crocker DE, Costa DP, Blackwell SB, Webb PM, Houser DS: Foraging ecology of northern elephant seals. Ecol Monogr 2000, 70:353-382.

8. Jonsen ID, Myers RA, Flemming JM: Meta-analysis of animal movement using state-space models. Ecology 2003, 84:3055-3063.

9. Morales JM, Haydon DT, Frair J, Holsinger KE, Fryxell JM: Extracting more out of relocation data: building movement models as mixtures of random walks. Ecology 2004, 85:2436-2445.

10. Patterson TA, Thomas L, Wilcox C, Ovaskainen O, Matthiopoulos J: State-space models of individual animal movement. Trends Ecol Evol 2008, 23:87-94.

11. Berliner M: Hierarchical Bayesian time series models. In Maximum Entropy and Bayesian Methods. Edited by Hanson K, Kluwer SR. ; 1996:15-22.

12. Schick RS, Loarie SR, Colchero F, Best BD, Boustany A, Conde DA, Halpin PN, Joppa LN, McClellan CM, Clark JS: Understanding movement data and movement processes: current and emerging directions. Ecol Lett 2008, 11:1338-1350.

13. Schick RS, Halpin PN, Read AJ, Slay CK, Kraus SD, Mate BR, Baumgartner MF, Roberts JJ, Best BD, Good CP, Loarie SR, Clark JS: Striking the right balance in right whale conservation. Can J Fish Aquat Sci 2009, 66:1399-1403.

14. Godley BJ, Blumenthal JM, Broderick AC, Coyne MS, Godfrey MH, Hawkes $L A$, Witt MJ: Satellite tracking of sea turtles: where have we been and where do we go next? Endanger Species Res 2008, 4:3-22.
15. Luschi P, Hays GC, Papi F: A review of long-distance movements by marine turtles, and the possible role of ocean currents. Oikos 2003, 103:293-302.

16. Morreale SJ, Standora EA, Spotila JR, Paladino FV: Migration corridor for sea turtles. Nature 1996, 384:319-320

17. Eckert SA, Sarti L: Distant fisheries implicated in the loss of the world's largest leatherback nesting population. Mar Turt News/ 1997, 78:2-7.

18. Shillinger GL, Palacios DM, Bailey H, Bograd SJ, Swithenbank AM, Gaspar P, Wallace BP, Spotila JR, Paladino FV, Piedra R, Eckert SA, Block BA: Persistent leatherback turtle migrations present opportunities for conservation. PLOS Biol 2008, 6:1408-1416.

19. Bailey H, Fossette S, Bograd SJ, Shillinger GL, Swithenbank AM, Georges J-Y, Gaspar P, Strömberg KHP, Paladino FV, Spotila JR, Block BA, Hays GC: Movement patterns for a critically endangered species, the leatherback turtle (Dermochelys coriacea), linked to foraging success and population status. PLoS One 2012, 7:e36401.

20. Bailey H, Benson SR, Shillinger GL, Bograd SJ, Dutton PH, Eckert SA, Morreale SJ, Paladino FV, Eguchi T, Foley DG, Block BA, Piedra R, Hitipeuw C, Tapilatu RF, Spotila JR: Identification of distinct movement patterns in Pacific leatherback turtle populations influenced by ocean conditions. Ecol Appl 2012, 22:735-747.

21. Shillinger $G$, Swithenbank AM, Bailey H, Bograd SJ, Castelton MR, Wallace BP, Spotila JR, Paladino FV, Piedra R, Block BA: Vertical and horizontal habitat preferences of post-nesting leatherback turtles in the South Pacific Ocean. Mar Ecol Prog Ser 2011, 422:275-289.

22. Hays GC, Marsh R: Estimating the age of juvenile loggerhead sea turtles in the North Atlantic. Can J Zool 1997, 75:40-46.

23. Hays GC, Luschi P, Papi F, Del Seppia C, Marsh R: Changes in behaviour during the inter-nesting period and post-nesting migration for Ascension Island green turtles. Mar Ecol Prog Ser 1999, 189:263-273.

24. Eckert SA: High-use oceanic areas for Atlantic leatherback sea turtles (Dermochelys coriacea) as identified using satellite telemetered location and dive information. Mar Biol 2006, 149:1257-1267.

25. Gaspar P, Georges JY, Fossette S, Lenoble A, Ferraroli S, Le Maho Y: Marine animal behaviour: neglecting ocean currents can lead us up the wrong track. Proc R Soc B 2006, 273:2697-2702.

26. Sale A, Luschi P: Navigational challenges in the oceanic migrations of leatherback sea turtles. Proc R Soc B 2009, 276:3737-3745.

27. Robel AA, Susan Lozier M, Gary SF, Shillinger GL, Bailey H, Bograd SJ: Projecting uncertainty onto marine megafauna trajectories. Deep Sea Res. Part I Oceanogr. Res. Pap 2011, 58:915-921.

28. Olson DB, Hitchcock GL, Ashjian AJMCJ, Peng G, Nero RW, Podestá GP: Life on the edge: marine life and fronts. Oceanography 1994, 7:52-60.

29. Girard C, Sudre J, Benhamou S, Roos D, Luschi P: Homing in green turtles Chelonia mydas: oceanic currents act as a constraint rather than as an information source. Mar Ecol Prog Ser 2006, 322:281-289.

30. Fossette S, Hobson VJ, Girard C, Calmettes B, Gaspar P, Georges J-Y, Hays GC: Spatio-temporal foraging patterns of a giant zooplanktivore, the leatherback turtle. J Mar Syst 2010, 81:225-234.

31. Eckert SA, Moore JE, Dunn DC, van Buiten RS, Eckert KL, Halpin PN: Modeling loggerhead turtle movement in the Mediterranean: importance of body size and oceanography. Ecol App/ 2008, 18:290-308.

32. Jonsen ID, Flemming JM, Myers RA: Robust state-space modeling of animal movement data. Ecology 2005, 86:2874-2880.

33. Wiens JA: Spatial scaling in ecology. Funct Ecol 1989, 3:385-397.

34. Urban DL, O'Neill RV, Shugart Jr HH: Landscape ecology. Bioscience 1987, 37:119-127.

35. Levin SA: The problem of pattern and scale in ecology. Ecology 1992 73:1943-1967.

36. Polovina JJ, Kobayashi DR, Parker DM, Seki MP, Balazs GH: Turtles on the edge: movement of loggerhead turtles (Caretta caretta) along oceanic fronts, spanning longline fishing grounds in the central North Pacific, 1997-1998. Fish Oceanogr 2000, 9:71-82.

37. Jonsen ID, Myers RA, James MC: Identifying leatherback turtle foraging behaviour from satellite telemetry using a switching state-space model. Mar Ecol Prog Ser 2007, 337:255-264.

38. Foster SD, Shimadzu H, Darnell R: Uncertainty in spatially predicted covariates: is it ignorable? J. R. Stat. Soc. Ser. C (Applied Stat 2012. no-no.

39. Park T, Casella G: The bayesian lasso. J Am Stat Assoc 2008, 103:681-686.

40. Zou H, Hastie T: Regularization and variable selection via the elastic net. J. R. Stat. Soc. Ser. B (Statistical Methodol 2005, 67:301-320 
41. Rockova V, Lesaffre E, Luime J, Löwenberg B: Hierarchical Bayesian formulations for selecting variables in regression models. Stat Med 2012, 31:1221-1237.

42. Hays GC, Houghton JDR, Isaacs C, King RS, Lloyd C, Lovell P: First records of oceanic dive profiles for leatherback turtles, Dermochelys coriacea, indicate behavioural plasticity associated with long-distance migration. Anim Behav 2004, 67:733-743.

43. Eckert SA, Eckert KL, Ponganis P, Kooyman GL: Diving and foraging behavior of leatherback sea turtles (Dermochelys coriacea). Can J Zool 1989, 67:2834-2840

44. Eckert SA, Bagley Kubis DS, Ehrhart L, Johnson C, Stewart K, DeFreese D: Internesting and postnesting movements and foraging habitats of leatherback Sea turtles (dermochelys coriacea) nesting in Florida. Chelonian Conserv. Biol 2006, 5:239-248.

45. Sale A, Luschi P, Mencacci R, Lambardi P, Hughes GR, Hays GC, Benvenuti S, Papi F: Long-term monitoring of leatherback turtle diving behaviour during oceanic movements. J. Exp. Mar. Bio. Ecol 2006, 328:197-210.

46. Hanks EM, Hooten MB, Johnson DS, Sterling JT: Velocity-based movement modeling for individual and population level inference. PLOS One 2011, 6:e22795.

47. Saba VS, Shillinger GL, Swithenbank AM, Block BA, Spotila JR, Musick JA, Paladino FV: An oceanographic context for the foraging ecology of eastern pacific leatherback turtles: consequences of ENSO. Deep Sea Res. Part I Oceanogr. Res. Pap 2008, 55:646-660.

48. Saba VS, Santidrian-Tomillo P, Reina RD, Spotila JR, Musick JA, Evans DA, Paladino FV: The effect of the El Niño Southern Oscillation on the reproductive frequency of eastern Pacific leatherback turtles. J Appl Ecol 2007, 44:395-404

49. Saba VS, Spotila JR, Chavez FP, Musick JA: Bottom-up and climatic forcing on the worldwide population of leatherback turtles. Ecology 2008, 89:1414-1427.

50. Dugdale RC, Barber RT, Chai F, Peng TH, Wilkerson FP: One-dimensional ecosystem model of the equatorial Pacific upwelling system. Part II: sensitivity analysis and comparison with JGOFS EqPac data. Deep Sea Res. Part II Top. Stud. Oceanogr 2002, 49:2747-2768.

51. Chai F, Dugdale RC, Peng TH, Wilkerson FP, Barber RT: One-dimensional ecosystem model of the equatorial Pacific upwelling system. Part I: model development and silicon and nitrogen cycle. Deep Sea Res. Part II Top. Stud. Oceanogr 2002, 49:2713-2745.

52. Shchepetkin AF, McWilliams JC: The regional oceanic modeling system (ROMS): a split-explicit, free-surface, topography-following-coordinate oceanic model. Ocean Model 2005, 9:347-404.

53. Cooper AB, Millspaugh JJ: The application of discrete choice models to wildlife resource selection studies. Ecology 1999, 80:566-575.

54. Roberts JJ, Best BD, Dunn DC, Treml EA, Halpin PN: Marine geospatial ecology tools: an integrated framework for ecological geoprocessing with ArcGIS, python, R, MATLAB, and C++. Environ Model Software 2010, 25:1197-1207.

55. R Core Team: R: a language and environment for statistical computing. 2012.

56. Clark JS: Models for ecological data: an introduction. Princeton University Press: Princeton; 2007.

57. Tsai T, Gill J, Rapkin J: Superdiag: R code for testing markov chain nonconvergence. 2012

58. Geweke J: Evaluating the accuracy of sampling-based approaches to the calculation of posterior moments. In Bayesian Stat. 4. Edited by Bernardo JM, Smith AFM, Dawid AP, Berger JO. Oxford, UK: Oxford University Press; 1992:169-193.

doi:10.1186/2051-3933-1-11

Cite this article as: Schick et al:: Pelagic movements of pacific leatherback turtles (dermochelys coriacea) highlight the role of prey and ocean currents. Movement Ecology 2013 1:11.

\section{Submit your next manuscript to BioMed Central and take full advantage of:}

- Convenient online submission

- Thorough peer review

- No space constraints or color figure charges

- Immediate publication on acceptance

- Inclusion in PubMed, CAS, Scopus and Google Scholar

- Research which is freely available for redistribution

Submit your manuscript at www.biomedcentral.com/submit 